\section{Tverrfaglig behandlingstilbud til pasienter med ryggsmerter ved et lokalsykehus}

ORIGINALARTIKKEL

\section{NICOLAY BLIX WERNER}

E-post: nico_werner@hotmail.com

Akershus universitetessykehus

Han har bidratt med observasjon av tiltaket, analyser og har skrevet manuskriptet.

Nicolay Blix Werner er lege i spesialisering og daglig leder i Sono Education.

Forfatteren har fylt ut ICMJE-skjemaet og oppgir ingen interessekonflikter.

\section{KJERSTI MYHRE}

Avdeling for fysikalsk medisin og rehabilitering

Oslo Universitetssykehus

Hun har bidratt med analyser og manuskriptutarbeiding.

Kjersti Myhre er ph.d. og overlege.

Forfatteren har fylt ut ICMJE-skjemaet og oppgir ingen interessekonflikter.

\section{ERIK L. WERNER}

Sørlandet Sykehus Arendal

og

Det medisinske fakultet

Universitetet i Oslo

Han har bidratt med utforming og gjennomføring av tiltaket og manuskriptutarbeiding.

Erik L. Werner er ph.d., lege og professor i allmennmedisin.

Forfatteren har fylt ut ICMJE-skjemaet og oppgir følgende interessekonflikter: Han har hatt 10 \% stilling som lege i Ryggpoliklinikken og fått støtte til kongress fra Ryggtilbudet.

\section{BAKGRUNN}

Ryggsmerter regnes som den hyppigste enkeltårsaken til sykefravær. Ved Sørlandet sykehus Arendal ble det i 2010 gjennom Raskere tilbake-ordningen etablert et tverrfaglig behandlingstilbud basert på gjeldende retningslinjer for ryggpasienter. I denne studien presenteres erfaringer fra seks år med behandlingstilbudet. 
Pasienter som ble henvist til Sørlandet sykehus Arendal i perioden 2011-16 på grunn av langvarige ryggplager, fikk tilbud om tverrfaglig behandling. Dette inkluderte individuell samtale med lege, fire uker gruppebasert ryggskole og fysioterapeutledet trening samt åtte uker med enten fysioterapeutveiledet trening eller egentrening. Sykmeldingsgrad og funksjonsnivå gjennom skår på Roland-Morris Disability Questionnaire (RMDQ) ble rapportert ved start og etter 4 og 12 uker.

\section{RESULTATER}

Totalt 433 yrkesaktive pasienter gjennomførte behandlingstilbudet. Gjennomsnittsalderen var 41,9 år og $52 \%$ var kvinner. 57 \% var sykmeldt ved start og de øvrige ble vurdert å ha høy risiko for å bli sykmeldt. 7,5\% av disse ble sykmeldt i løpet av observasjonsperioden, mens $28,5 \%$ av de sykmeldte ble helt friskmeldt. 52,7\% av pasientene hadde klinisk signifikant reduksjon i RMDQ-skår (> 3,5 poeng).

\section{FORTOLKNING}

Det tverrfaglige behandlingstilbudet synes å bedre funksjonen og redusere sykefraværet hos pasienter med langvarige ryggplager. Denne studien har kort oppfølgingstid og ingen kontrollgruppe, så observasjonene må derfor tolkes med forsiktighet.

Ryggplager er et helseproblem for den enkelte og for samfunnet. Ingen annen lidelse rammer så mange og fører til mer arbeidsuførhet (1). Direkte og indirekte kostnader er 13-15 milliarder kroner årlig i Norge (2).

Akutte, uspesifikke korsryggssmerter går som regel over av seg selv innen få uker (2-4).Ved varighet over 6-8 uker anbefaler man både i norske og i europeiske retningslinjer en tverrfaglig behandling med fysisk trening og kognitiv terapi $(2,5)$.

Sørlandet Sykehus Arendal var i 1997 blant de første i Norge som opprettet en ryggpoliklinikk (6). Man ønsket en felles dør inn til spesialisthelsetjenesten for alle ryggpasienter. Pasientene ble undersøkt av lege og/eller fysioterapeut og deretter vurdert for kirurgisk behandling eller konservativ behandling i treningsgrupper (6). I perioden 2010-18 var tilbudet organisert som et Raskere tilbake-tiltak.

I denne studien ønsket vi å kartlegge eventuelle endringer i funksjon og sykefravær hos pasientene som gjennomførte behandlingstilbudet.

\section{Materiale og metode}

Dette er en deskriptiv gjennomgang av data fra pasienter med langvarige korsryggssmerter som fikk behandlingstilbud ved Sørlandet sykehus Arendal i tidsrommet 15.8.2011-31.12.2016.

Publisering av dataene er vurdert av Regional etisk komité $\emptyset \emptyset$ r-Øst (REK) som ikkesøknadspliktig, og Norsk senter for forskningsdata (NSD) har ikke hatt innsigelser.

\section{DELTAKERE}

Alle pasientene var henvist til ryggpoliklinikken fra fastlegen på grunn av korsryggssmerter som hadde vart mer enn 4-6 uker, og som var eller hadde høy risiko for å bli sykmeldt. Pasientene fikk først en klinisk undersøkelse av fysioterapeut, som i samråd med en nevrolog avgjorde om pasienten skulle tilbys konservativ behandling eller vurderes $\mathrm{i}$ tverrfaglig ryggmøte med ortoped og radiolog med tanke på operasjon. Pasientene som ble anbefalt konservativ behandling, ble invitert til å delta i ryggtilbudet. De pasientene som først ble sendt til vurdering for operasjon, men som i tverrfaglig møte ble anbefalt konservativ behandling, ble også invitert til å delta i ryggtilbudet. Pasientene kunne ha korsryggssmerter med eller uten nerverotaffeksjon, men var uten operasjonsindikasjon, og 
man hadde utelukket alvorlig underliggende årsak til smertene.

Siden Raskere tilbake er knyttet til sykefravær, var det noen pasienter som falt utenom disse kriteriene. Det gjaldt pensjonister, studenter, arbeidsledige, hjemmeværende og de som allerede hadde arbeidsavklaringspenger eller uføretrygd. Disse fikk delta i tiltaket dersom det var ledige plasser på kursene. Dette gjaldt for 101 pasienter, som ikke omtales nærmere i denne artikkelen.

\section{BEHANDLINGSTILBUDET}

Pasientene som valgte å delta i behandlingstilbudet møtte først til en 30 minutters konsultasjon med lege med lang erfaring med ryggplager. Formålet med konsultasjonen var å få frem eventuelle negative tanker, yrkesaktivitetshindringer og feiloppfatninger som kunne tenkes å bidra til å kronifisere plagene. Deretter ble pasientene inkludert i grupper på seks til åtte personer som møttes tre ganger i løpet av tre uker. Det var ingen stratifisering til gruppene. Møtene var ledet av to erfarne fysioterapeuter og besto først av to timer undervisning $\mathrm{i}$ anatomi og smertefysiologi samt gruppesamtale om ryggplagenes påvirkning på dagliglivet og uhensiktsmessige tolkninger av smertene. Deretter var det en time med bevegelsestrening. Fysioterapeutenes oppgave var å veilede pasientene og å gjøre dem oppmerksomme på eventuelle avvergingsbevegelser og unngåelsesatferd. Når pasientene stoppet opp for å unngå smerte, ble de oppfordret til å fortsette. Målet var å gjøre dem trygge på å kunne være i normal aktivitet.

Etter de fire ukene møtte pasientene til en times individuell konsultasjon med en av fysioterapeutene. Her ble de viktigste punktene fra undervisningen gjennomgått på nytt, i tillegg til at pasienten skrev ned egne mål for videre trening og arbeid de neste åtte ukene. I disse åtte ukene kunne pasientene velge mellom egentrening og å fortsette ukentlig trening i fysioterapiledet gruppe. Alle møtte til en endelig evaluering med fysioterapeut til slutt.

\section{REGISTRERINGER}

Vi registrerte kjønn og alder, status for yrkesaktivitet og grad av sykmelding. I tillegg registrerte vi funksjonssvikt ved hjelp av Roland-Morris Disability Questionnaire (RMDQ), som er et selvutfyllingsskjema med 24 utsagn som beskriver fysiske begrensninger grunnet ryggsmerter (7). For å forsikre seg om at svaret er relatert til ryggsmertene, inneholder hvert utsagn "på grunn av min ryggsmerte ...», og det er den aktuelle situasjonen på svartidspunktet som gjelder. Hvert utsagn gir ett poeng, og pasienten får en skår mellom o og 24. Jo høyere skår, jo større funksjonssvikt.

\section{UTFALLSMÅL}

Det primære utfallsmålet var endring av funksjon besvart ved RMDQ-skjemaet. I tråd med nyere studier valgte vi å anse en endring på 3,5 poeng som klinisk signifikant $(8,9)$. Det sekundære utfallsmålet var endring i sykmeldingsstatus. Pasientene rapporterte selv i hvilken grad de var sykmeldt.

Både RMDQ-skår og sykmelding ble registrert ved start, ved fire uker og ved 12 uker.

Vi ønsket også å se om det var forskjell mellom pasientene som valgte egentrening og de som valgte å fortsette ukentlig gruppetrening i de siste åtte ukene.

\section{STATISTIKK}

Data er registrert fortløpende i studieperioden og analysert i SPSS (IBM SPSS, versjon 23, SPSS inc., Chicago, IL, USA).

Endring i RMDQ-skår ble registrert som kontinuerlig variabel. Vi brukte paret t-test for å undersøke endringene. For å unders $ø$ ke forskjell i gruppene med egentrening versus gruppetrening brukte vi uavhengig t-test og khikvadrattest.

I Raskere tilbake-gruppen talte vi opp antall pasienter som var sykmeldt eller ikke. Sykmeldingsprosenten ble registrert ved oppstart og etter 12 uker. I gruppen som var 
sykmeldt ved oppstart, undersøkte vi en eventuell korrelasjon mellom endring i RMDQskår og endring i sykmeldingsprosent med lineær regresjonsanalyse. Endring $\mathrm{i}$ sykmeldingsprosent fra start til 12 uker var den avhengige variabelen, mens endring $\mathrm{i}$ RMDQ-skår fra start til 12 uker var uavhengig variabel. Vi kontrollerte for alder, kjønn og aktuell sykmeldingsprosent på starttidspunktet. Signifikansnivået ble satt til $5 \%$.

\section{Resultater}

Totalt 563 pasienter påbegynte ryggtilbudet ved Sørlandet Sykehus Arendal fra høsten 2011 til og med 2016. Antall pasienter økte per år, fra 41 i 2011 til 109 i 2016. Vi har ikke data på de pasientene som takket nei til tilbudet. Det var fire pasienter som avbrøt behandlingen og vi mangler 12 ukers data for 25 pasienter. Totalt ble 433 pasienter inkludert. Tabell 1 viser demografiske data for disse pasientene ved inklusjonstidspunktet.

\section{Tabell 1}

Yrkesaktive pasienter $(\mathrm{N}=433)$ som fullførte ryggbehandlingstilbudet ved Sørlandet sykehus Arendal i perioden 2011-16 og takket ja til å bli med i studien. Antall (\%) dersom annet ikke er angitt. RMDQ = Roland Morris Disability Questionnaire, skala o-24 (7).

\begin{tabular}{|lr|}
\hline & $\begin{array}{r}\text { Pasienter } \\
(\mathbf{N}=433)\end{array}$ \\
\hline Gjennomsnittlig alder, år (SD) & $41,9(11,0)$ \\
\hline Kvinner & $224(51,7)$ \\
\hline Gjennomsnittlig RMDQ-skår ved start (SD) & $9,3(4,4)$ \\
\hline Yrkesstatus ved start & \\
\hline I arbeid & $187(43,2)$ \\
\hline Sykmeldt < 20\% & $9(2,1)$ \\
\hline Sykmeldt 20-80\% & $84(19,4)$ \\
\hline Sykmeldt > 80\% & $153(35,3)$ \\
\hline
\end{tabular}

Ved oppstart var gjennomsnittlig RMDQ-skår 9,5 poeng hos kvinner og 9,1 poeng hos menn $(\mathrm{p}=0,28) .126$ av de 209 mennene (6o,3\%) og 120 av de 224 kvinnene (53,6\%) var sykmeldt ved inklusjon $(\mathrm{p}=\mathrm{o}, 19)$.

Gjennomsnittlig RMDQ-skår for de 433 pasientene var 9,3 (SD 4,4) ved start, 6,3 (SD 4,2) etter fire uker og 5,3 (SD 4,5) etter 12 uker. Gjennomsnittlig endring fra start til fire uker var 3,o poeng ( $95 \% \mathrm{KI}$ 2,7-3,4) og fra start til 12 uker 4,o poeng ( $95 \% \mathrm{KI}$ 3,6-4,5) (begge $\mathrm{p}<0$,oo1). 228 pasienter (52,7\%) hadde en klinisk signifikant reduksjon (>3,5 poeng) i RMDQ-skår etter 12 uker. Det var 13 (3,0 \%) som hadde en klinisk signifikant økning, mens 192 (44,3\%) hadde ingen endring.

Pasienter med egentrening $(n=172)$ hadde en gjennomsnittlig bedring av RMDQ-skår på 3,5, sammenliknet med 4,5 for de som hadde gruppetrening $(p=0,026)$.

Av 246 sykmeldte var det 16 (6,5\%) som hadde økt sykmeldingsgrad etter 12 uker, 118 (48\%) var helt $(n=70)$ eller delvis $(n=48)$ friskmeldt. 14 av de $187(7,5 \%)$ ikke-sykmeldte ved start var sykmeldt etter 12 uker.

Vi fant ingen signifikant sammenheng mellom egentrening versus gruppetrening og reduksjon i sykmeldingsprosenten blant de sykmeldte pasientene $(\mathrm{p}=0,588)$.

Resultat fra den lineære regresjonsanalysen er vist i tabell 2. Verken alder eller kjønn var signifikant assosiert med endring i sykmeldingsprosenten etter 12 uker. En reduksjon $\mathrm{i}$ RMDQ-skår ved 12 uker var signifikant assosiert med en reduksjon i

sykemeldingsprosenten. Vår modell forklarte $23 \%$ av sykfraværets variabilitet. 
Lineær regresjonsanalyse med endring av RMDQ-skår som prediktor og endring i sykmeldingsprosent etter 12 uker som avhengig variabel hos sykmeldte pasienter med ryggsmerter som fullførte ryggbehandlingstilbudet ved Sørlandet sykehus Arendal 2011-16 $(\mathrm{n}=246)$. Vi har justert for alder, kjønn og sykmeldingsprosent ved oppstart. RMDQ = Roland Morris Disability Questionnaire. Både endring i sykmeldingsprosent og RMDQ-skår er kontinuerlige variabler, positiv verdi på endring av RMDQ er bedring i funksjon, positiv verdi på endring i sykefravær tilsvarer redusert sykmeldingsprosent.

\begin{tabular}{|lr|}
\hline Variabel & Ustandardisert $\beta(\mathbf{9 5} \% \mathbf{K I})$ \\
\hline Alder (år) & $0,13(-0,29-0,551)$ \\
\hline Kjønn (mann vs. kvinne ) & $8,81(-0,271-17,88)$ \\
\hline Sykmeldingsprosent ved studiestart & $0,32(0,153-0,494)$ \\
\hline Endring RMDQ-skår (0-12 uker) & $3,25(2,31-4,20)$ \\
\hline
\end{tabular}

\section{Diskusjon}

I denne studien har vi vist at ryggpasienter som deltok i et gruppebasert behandlingstilbud ved sykehuset, reduserte funksjonssvikten, og at halvparten av deltagerne hadde gjenopptatt yrkesaktivitet helt eller delvis 12 uker etter behandlingsstart.

Det er viktig å bemerke at ryggtilbudet ved Sørlandet Sykehus Arendal ble etablert som et Raskere tilbake-tilbud og ikke som et forskningsprosjekt. Vi har derfor ingen kontrollgruppe og kan ikke si noe sikkert om effekten av behandlingstilbudet sett mot det naturlige forløpet. Vi mangler også data på varighet av ryggsmerter og sykefravær før inklusjon og har heller ikke registrert komorbiditet eller andre demografiske, sosiale eller psykologiske faktorer som kan påvirke forekomst og varighet av ryggplager og sykefravær $(10,11)$. Andre faktorer enn bedret funksjon kan også ha hatt betydning for reduksjon av sykefraværet. Alle data i denne studien er selvrapportert, hvilket kan innebære mindre pålitelige data enn man har i offentlige registre. Studien har en kort observasjonstid og blir derfor mest å betrakte som et situasjonsbilde.

Til tross for disse begrensningene mener vi at denne studien har interessante funn, da dette er data fra en klinisk virkelighet i et mye benyttet behandlingstilbud. Tilsvarende tilbud er nå etablert ved de fleste sykehus i Norge. Vi registrerte mange pasienter, hadde lite frafall og benyttet enkle inklusjons- og eksklusjonskriterier som reflekterer den heterogene pasientgruppen som henvises til slike tilbud. Det har i tillegg vært få behandlere i prosjektet, og innholdet har ikke blitt vesentlig endret i løpet av observasjonsperioden.

Vi fant at $28,5 \%$ av pasientene som var sykmeldt ved inklusjon, var tilbake i $100 \%$ jobb etter 12 uker. Dette samsvarer med resultatene fra en prospektiv kohortstudie av 71 sykmeldte ryggpasienter som deltok i et Raskere tilbake-tiltak ved Ålesund sjukehus, der 31 \% var tilbake i jobb 12 uker etter inklusjon (12).

I en klyngerandomisert studie fra osloregionen i 2016 , COPE-studien, ble andelen sykmeldte redusert fra $36 \%$ ved inklusjon til $9 \%$ etter 12 uker i intervensjonsgruppen, mens andelen sykmeldte i kontrollgruppen ble redusert fra $28 \%$ til 15\%(13). Dette er imidlertid en studie fra primærhelsetjenesten, der pasientene ikke nødvendigvis er like de som er henvist til spesialisthelsetjenesten. Sammenligning med andre norske studier er vanskelig fordi studiene har benyttet ulike utfallsmål og gjort sine målinger på forskjellige tidspunkt (14, 15).

Pasientene hadde en gjennomsnittlig bedring i funksjon på 4,o RMDQ-poeng i løpet av 12 uker. Til tross for at RMDQ-skår er hyppig benyttet som uttrykk for funksjon hos ryggpasienter, er det fortsatt usikkert hvor stor endring som er klinisk relevant $(7-9,16,17)$. Vår vurdering om endring på 3,5 poeng som klinisk signifikant, baserer seg på en 
oversiktsartikkel fra $2005(8)$.

Mens COPE-studien også benyttet RMDQ som funksjonsskår, brukte Ålesund-studien Oswestry Disability Index (ODI). For dette funksjonsmålet regnes en reduksjon over 1o poeng som klinisk signifikant (8). Vi kan ikke direkte sammenligne disse skalaene, men begge gir utrykk for pasientens egenrapporterte funksjon. Også i studien fra Ålesund fant man en klinisk signifikant reduksjon (21,2 poeng) etter 12 uker. Studien hadde i likhet med vår studie ingen kontrollgruppe (12). I COPE-studien ble RMDQ-skår rapportert etter 4-5 uker. Både pasientene i intervensjonsgruppen og $\mathrm{i}$ kontrollgruppen hadde en bedring $\mathrm{i}$ funksjon på henholdsvis 4,1 og 4,3 poeng (13), som er noe bedre enn blant våre pasienter (3,0 etter fire uker). I COPE-studien ble likheten mellom gruppene forklart med at også kontrollgruppen gjennomgikk en intervensjon som i praksis var svært lik innholdet i intervensjonsgruppen (13).

En studie fra en tverrfaglig ryggpoliklinikk i Bergen i 2011 viste en noe mindre reduksjon i RMDQ-skår (2,9 poeng) (18). Tiltaket skiller seg imidlertid fra vår studie ved at det kun varte i tre og en halv uke, var mer intensivt og ved hjelp av kognitiv atferdsterapi spesifikt rettet mot frykt og unngåelsesatferd. En randomisert kontrollert studie fra Oslo universitetssykehus med 250 pasienter med degenerative korsryggssmerter viste ingen forskjell i behandling med glukosaminer eller placebo i 12 uker (19). Disse pasientene hadde en reduksjon i RMDQ-skår på henholdsvis 3,4 og 3,2 poeng og kan indikere det naturlige forløpet hos pasientgruppen (19).

En oppdatert oversiktsartikkel fra Cochrane om ryggskole, definert som undervisning og trening, viser ingen sikker effekt av intervensjoner på verken funksjon, smerte eller sykmelding, verken ved akutte, subakutte eller kroniske ryggplager i forhold til annen behandling, placebo eller ingen behandling (20, 21). Det påpekes imidlertid at ingen av de inkluderte studiene i denne oversikten var av høy kvalitet. Høy heterogenitet gjør også sammenligninger svært vanskelig $(20,21)$.

I en annen oversiktsartikkel fra Cochrane om tverrfaglig biopsykososial behandling, som sannsynligvis er mer sammenlignbart med vårt behandlingstilbud, ble det funnet effekt på både funksjon, smerte og sykmelding for subakutte ryggplager, sammenlignet med standard behandling. Effekten av denne behandlingsmetoden sammenlignet med andre er mer usikker (22). For kroniske ryggplager er slik behandling mer effektiv på smerte og funksjon enn standard behandling og fysioterapi, mens den for sykmelding kun er mer effektiv enn fysioterapi (23).

Vi har i denne observasjonsstudien beskrevet erfaringer fra drøyt fem år med et behandlingstilbud i spesialisthelsetjenesten som er basert på gjeldende retningslinjer og i hovedsak er det konservative tilbudet som ryggpasienter i Norge får. Studiedesignet gjør at vi ikke kan trekke sikre konklusjoner med hensyn til effekt, men vi konstaterer at pasientene har bedret sin funksjon og at nesten halvparten ble helt eller delvis friskmeldt etter 12 uker.

\section{HOVEDFUNN}

433 yrkesaktive pasienter med korsryggssmerter fullførte et Raskere tilbake-tilbud ved Sørlandet Sykehus Arendal i perioden 2011-16

Over halvparten hadde en klinisk signifikant bedret funksjonsskår etter 12 uker

Nesten halvparten av de sykmeldte gikk helt eller delvis tilbake til jobb 
2. Lærum EBJ, Storheim K, Espeland A et al. Nasjonale retningslinjer for Korsryggsmerter med og uten nerverotaffeksjon. Oslo: Formidlngs- og forskningsenheten for muskel- og skjelettlidelser (FORMI) og Sosial- og helsedirektoratet, 2007.

https://manuellterapi.no/wp-content/uploads/2017/05/Nasjonale-kliniske-retningslinjer-for-korsryggs merter-med-og-uten-nerverotaffeksjon.pdf Lest 15.5.2019.

3. Pengel LH, Herbert RD, Maher CG et al. Acute low back pain: systematic review of its prognosis. BMJ 2003; 327:323. [PubMed][CrossRef]

4. van Tulder M, Becker A, Bekkering T et al. Chapter 3. European guidelines for the management of acute nonspecific low back pain in primary care. Eur Spine J 2006; 15 (suppl 2): S169-91.

[PubMed][CrossRef]

5. Airaksinen O, Brox JI, Cedraschi C et al. Chapter 4. European guidelines for the management of chronic nonspecific low back pain. Eur Spine J 2006; 15 (suppl 2): S192-300. [PubMed][CrossRef]

6. Soldal D, Reiso H. Ryggpoliklinikk-foreløpige erfaringer fra Aust-Agder. Tidsskr Nor Lægeforen 2002; 122:1797-9. [PubMed]

7. Roland M, Fairbank J. The Roland-Morris Disability Questionnaire and the Oswestry Disability Questionnaire. Spine 2000; 25:3115-24. [PubMed][CrossRef]

8. Ostelo RW, de Vet HC. Clinically important outcomes in low back pain. Best Pract Res Clin Rheumatol 2005; 19:593-607. [PubMed][CrossRef]

9. Kovacs FM, Abraira V, Royuela A et al. Minimal clinically important change for pain intensity and disability in patients with nonspecific low back pain. Spine 2007; 32: 2915-20. [PubMed][CrossRef]

10. Grotle M, Vøllestad NK, Veierød MB et al. Fear-avoidance beliefs and distress in relation to disability in acute and chronic low back pain. Pain 2004; 112:343-52. [PubMed][CrossRef]

11. Oyeflaten I, Hysing M, Eriksen HR. Prognostic factors associated with return to work following multidisciplinary vocational rehabilitation. J Rehabil Med 2008; 40: 548-54. [PubMed][CrossRef]

12. Grotle MKL, Kopperstad A. Sykefravær og «Raskere tilbake»: En prospektiv klinisk studie av pasienter med langvarige ryggsmerter. Fysioterapeuten 2016; 83: 26-31.

13. Werner EL, Storheim K, Løchting I et al. Cognitive patient education for low back pain in primary care: A cluster randomized controlled trial and cost-effectiveness analysis. Spine 2016; 41: 455-62. [PubMed][CrossRef]

14. Myhre K, Marchand GH, Leivseth G et al. The effect of work-focused rehabilitation among patients with neck and back pain: a randomized controlled trial. Spine 2014;39:1999-2006.

[PubMed][CrossRef]

15. Storheim K, Brox JI, Holm I et al. Predictors of return to work in patients sick listed for sub-acute low back pain: a 12-month follow-up study. J Rehabil Med 2005; 37:365-71. [PubMed][CrossRef]

16. Stratford PW, Binkley JM, Riddle DL et al. Sensitivity to change of the Roland-Morris Back Pain Questionnaire: part 1. Phys Ther 1998; 78: 1186-96. [PubMed][CrossRef]

17. Monticone M, Baiardi P, Vanti C et al. Responsiveness of the Oswestry Disability Index and the Roland Morris Disability Questionnaire in Italian subjects with sub-acute and chronic low back pain. Eur Spine J 2012; 21: 122-9. [PubMed][CrossRef]

18. Strand LI, Anderson B, Lygren $\mathrm{H}$ et al. Responsiveness to change of 10 physical tests used for patients with back pain. Phys Ther 2011; 91: 404-15. [PubMed][CrossRef]

19. Wilkens P, Scheel IB, Grundnes O et al. Effect of glucosamine on pain-related disability in patients with chronic low back pain and degenerative lumbar osteoarthritis: a randomized controlled trial. JAMA 2010; 304: 45-52. [PubMed][CrossRef]

20. Parreira P, Heymans MW, van Tulder MW et al. Back Schools for chronic non-specific low back pain. Cochrane Database Syst Rev 2017; 8: CDo11674. [PubMed]

21. Poquet N, Lin CW, Heymans MW et al. Back schools for acute and subacute non-specific low-back pain. Cochrane Database Syst Rev 2016; 4: CDoo8325. [PubMed]

22. Marin TJ, Van Eerd D, Irvin E et al. Multidisciplinary biopsychosocial rehabilitation for subacute low back pain. Cochrane Database Syst Rev 2017; 6: CDoo2193. [PubMed] 
23. Kamper SJ, Apeldoorn AT, Chiarotto A et al. Multidisciplinary biopsychosocial rehabilitation for chronic low back pain: Cochrane systematic review and meta-analysis. BMJ 2015; 350: h444.

[PubMed][CrossRef]

Publisert: 19. september 2019. Tidsskr Nor Legeforen. DOI: 10.4045/tidsskr.18.0083

Mottatt 23.1.2018, første revisjon innsendt 21.9.2018, godkjent 15.5.2019.

(C) Tidsskrift for Den norske legeforening 2020. Lastet ned fra tidsskriftet.no 